\title{
Assessing the Binding of Venoms from Aquatic Elapids to the Nicotinic Acetylcholine Receptor Orthosteric Site of Different Prey Models
}

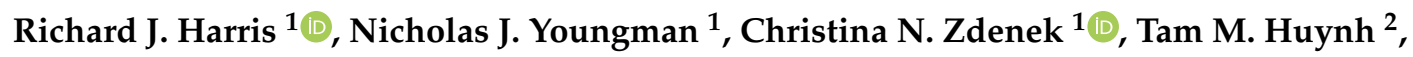 \\ Amanda Nouwens ${ }^{3}$, Wayne C. Hodgson ${ }^{2}$, David Harrich ${ }^{4} \oplus$, Nathan Dunstan ${ }^{5}$, \\ José A. Portes-Junior ${ }^{6}$ and Bryan G. Fry ${ }^{1, *(D)}$ \\ 1 Toxin Evolution Lab, University of Queensland, Biological Sciences, St. Lucia, QLD 4072, Australia; \\ rharris2727@gmail.com (R.J.H.); christinazdenek@gmail.com (C.N.Z.); n.youngman@uq.edu.au (N.J.Y.) \\ 2 Department of Pharmacology, Biomedicine Discovery Institute, Monash University, Clayton, \\ VIC 3800, Australia; tlhuy3@student.monash.edu (T.M.H.); wayne.hodgson@monash.edu (W.C.H.) \\ 3 School of Chemistry and Molecular Biosciences, University of Queensland, St Lucia, QLD 4072, Australia; \\ a.nouwens@uq.edu.au \\ 4 QIMR Berghofer, Royal Brisbane Hospital, Herston, QLD 4029, Australia; \\ david.harrich@qimrberghofer.edu.au \\ 5 Venom Supplies, Tanunda, SA 5352, Australia; nathan@venomsupplies.com \\ 6 Laboratório de Coleções Zoológicas, Instituto Butantan, São Paulo 05503-900, Brazil; \\ portes.junior@butantan.gov.br \\ * Correspondence: bgfry@uq.edu.au; Tel.: +61-7-336-58515
}

Received: 7 September 2020; Accepted: 2 October 2020; Published: 6 October 2020

\begin{abstract}
The evolution of an aquatic lifestyle from land dwelling venomous elapids is a radical ecological modification, bringing about many evolutionary changes from morphology to diet. Diet is an important ecological facet which can play a key role in regulating functional traits such as venom composition and prey-specific targeting of venom. In addition to predating upon novel prey (e.g., fish, fish eggs and invertebrates), the venoms of aquatic elapids also face the challenge of increased prey-escape potential in the aquatic environment. Thus, despite the independent radiation into an aquatic niche on four separate occasions, the venoms of aquatic elapids are evolving under convergent selection pressures. Utilising a biolayer interferometry binding assay, this study set out to elucidate whether crude venoms from representative aquatic elapids were target-specific to the orthosteric site of postsynaptic nicotinic acetylcholine receptor mimotopes of fish compared to other terrestrial prey types. Representatives of the four aquatic lineages were: aquatic coral snakes representative was Micrurus surinamensis;, sea kraits representative was Laticauda colubrina; sea snakes representatives were two Aipysurus spp. and eight Hydrophis spp; and water cobras representative was Naja annulata. No prey-specific differences in crude venom binding were observed from any species tested, except for Aipysurus laevis, which showed slight evidence of prey-potency differences. For Hydrophis caerulescens, H. peronii, H. schistosus and M. surinamensis, there was a lack of binding to the orthosteric site of any target lineage. Subsequent testing on the in vitro chick-biventer cervicis muscle preparation suggested that, while the venoms of these species bound postsynaptically, they bound to allosteric sites rather than orthosteric. Allosteric binding is potentially a weaker but faster-acting form of neurotoxicity and we hypothesise that the switch to allosteric binding is likely due to selection pressures related to prey-escape potential. This research has potentially opened up the possibility of a new functional class of toxins which have never been assessed previously while shedding light on the selection pressures shaping venom evolution.
\end{abstract}

Keywords: Elapidae; venom; neurotoxicity; nicotinic acetylcholine receptors; orthosteric; allosteric 


\section{Introduction}

The evolution of an aquatic lifestyle (both marine and freshwater) from land-dwelling snakes requires radical morphological and ecological changes [1-3]. This shift to an aquatic environment has evolved on at least four independent occasions across the Elapidae family of snakes: once in the cobras (water cobra clade; Naja annulata and N. christyi), once in the coral snakes (the Amazonian coral snake; Micrurus surinamensis), once in the Asian elapids (sea kraits; Laticauda spp.), and once in the Australian elapids (sea snakes; last common ancestor of Aipysurus and Hydrophis) [4]. This change in environment has further led to major alterations in their diet preference [1], from terrestrial vertebrates such as amphibians, reptiles, mammals and birds to fish, fish eggs and marine invertebrates [5-7]. These changes in diet are likely to require a different venom composition and possibly pathophysiological modes of targeting in comparison to their terrestrial counterparts. For example, a diet shift can alter venom function; some species (e.g., Aipysurus eydouxii and Emydocephalus spp.) have subsequently shifted to feeding exclusively on fish eggs, consequently bringing about the atrophy and loss of their venom glands [5,8]. A focus on aquatic prey types is also likely to be the primary reason why many sea snakes have extraordinarily potent neurotoxic venoms [9], as they need to quickly immobilise fish prey that have a high escape potential. This is particularly important given that sea snakes likely lack post-envenomation scent cues in the aquatic medium, which terrestrial snakes depend upon, since their olfactory organs are highly degenerated compared to terrestrial snakes [10]. This would, in turn, likely mean that they cannot follow envenomed prey as effectively as their terrestrial relatives. Another reason for this prominent neurotoxicity in sea snake venom might be that other pathophysiological functions such as coagulotoxicity are likely not as effective on simpler/divergent circulatory systems of fish and marine invertebrates in comparison to terrestrial vertebrates as mammals and birds [11,12].

Neurotoxicity produced by elapid venoms is predominately caused by three-finger toxins (3FTxs) that target the muscle-type $\alpha-1$ nicotinic acetylcholine receptor (nAChR) at the postsynaptic terminal of the neuromuscular junction [13-16]. Studies have consistently revealed that 3FTxs have a particular affinity for blocking of the $\alpha-1$ orthosteric site (acetylcholine binding region) at amino acid positions 187-200, with specific key residues in this region being their primary target [17-21]. This mode of action causes flaccid paralysis by preventing the neurotransmitter acetylcholine (ACh) from binding, which would otherwise trigger muscular contractions $[13,22]$. The toxins that target the postsynaptic site are classed as $\alpha$-neurotoxins [13].

3FTxs are a non-enzymatic toxin class that are ubiquitous throughout the elapids $[13,14]$ and have been found in some colubrids [23-26] and other advanced snakes [27]. It was revealed that 3FTxs are under positive diversifying selection [28], with small amino acid changes likely allowing for the alteration in target specificity and function. The neurotoxicity of 3FTxs by targeting nAChRs seems to be the dominant pathophysiology, however, some 3FTxs have been shown to utilise different methods of neurotoxic targeting such as blocking of adrenergic receptors [29,30], acid-sensing (ASIC1) channels [31], L-type $\mathrm{Ca}^{2+}$ channels [32], muscarinic receptors [33-35], and sodium ion channels [36], as well as inhibiting acetylcholinesterase [37]. Other functions, such as coagulotoxicity [38-40] and cytotoxicity [41,42], are also exploited by 3FTxs. In combination with the diversity of pathophysiological targets of 3FTxs, they can also exhibit prey-specificity [23-26,43-46]. Clearly, 3FTxs are a widely diverse toxin class and, as such, venoms rich in 3FTxs are ideal to further explore their evolution, biochemistry and pharmacology.

The venom compositions of many aquatic snakes are composed mostly of neurotoxic 3FTxs-in some cases $>75 \%$ of the venom composition—along with phospholipase $\mathrm{A}_{2}\left(\mathrm{PLA}_{2}\right)$ toxins [47-53]. Given the rapid onset of neurotoxic pathologies produced by many neurotoxins within these toxin classes, venoms possessing large proportions of these toxin types again suggest the need for fast immobilisation as a key selection pressure in aquatic environments.

This study initially set out to determine whether the change in ecological niche of aquatic elapids (two Aipysurus, eight Hydrophis, one Laticauda, one Micrurus and one Naja species) has led to the development of prey-specific venom effects, particularly to that of their likely natural prey (fish). 
This was conducted utilising a well-established bio-layer interferometry (BLI) assay designed to test the binding of $\alpha$-neurotoxic venoms to the orthosteric site of taxa-specific nAChR mimotopes (small molecules that mimic part of the epitope) [54-56]. However, through unexpected initial findings, the study further addressed some new questions regarding the biochemistry and pharmacology of the venoms tested, such as the potential for allosteric targeting toxins within aquatic elapid venoms, which has never been assessed

\section{Results and Discussion}

Screening of aquatic elapid crude venoms to determine the potential for prey-specific binding of $\mathrm{nAChR}$ orthosteric mimotopes revealed some interesting and unexpected facets. Firstly, addressing our initial investigation, there is no true prey-specific targeting between all the species tested (Figure 1), or at least for the prey taxa mimotopes we assessed. This is indicated by the wavelength shift curves being particularly close/overlapping for the majority of the taxa mimotopes. Aipysurus laevis binds slightly more to the fish than the other taxa mimotopes, however true prey-selective venom would either be disproportionately higher than all other mimotope values, as seen with Ophiophagus hannah preferentially targeting the snake mimotope $[55,56]$, or it would be the only mimotope that showed binding. In the case of $A$. laevis, the fish, amphibian and bird/eel mimotope curves are clustered together (Figure 1), which is not indicative of preferential prey binding. This is also consistent with the fish orthosteric site, differing from the amphibian by only two amino acids, one of which (D for E) is a biochemically conserved substitution and unlikely to change binding. Similarly, the fish differed from the bird/eel by only one amino acid (bird orthosteric site is the same sequence as the representative eel sequence). Thus, the similar level of binding was consistent with the biochemical similarities of these three orthosteric sites.

Further to this, the $\alpha-1 \mathrm{nAChR}$ (chrna1) sequence for the 'eel' representative is a freshwater species (Gymnotus electricus; Anguilliformes (P09688)), which would not be a prey target for the marine aquatic elapids, and thus might not be truly representative of true prey. Although this sequence seems conserved between other freshwater eel lineages (e.g., Mastacembelus armatus; Synbranchiformes (A0A3Q3LHR6)), there are no sequenced marine representatives with which to compare. Thus, it is uncertain if the freshwater Gymnotus electricus sequence remains conserved across other marine families, including its closely related marine anguilliform relatives which are prey to many sea snakes [6]. Evidence has suggested there is resistance within the marine eels Gymnothorax moringa, G. hepaticus and G. undulatus (Gymnotiformes) to Laticauda colubrina and A. laevis venom [57,58], whereas Anguilla rostrata (Anguilliformes) were not resistant [57]. However, it is unclear if this resistance is seen at the nAChR orthosteric site, similarly to other species' resistance to elapid 3FTxs [59-61]. Once more sequences for marine eel representatives become publicly available, future research should endeavour to test sea snake venom against these sequences to assess their binding and potential resistance.

Some aquatic elapids are also known to feed on marine invertebrates [6,7], which no mimotope representatives were tested against in this study. Invertebrates may show a different binding and/or prey-selective targeting by some of the aquatic elapid venoms, particularly the species that have relatively low binding to the BLI assay (Figure 1). Invertebrate-specific venom has been found within some species of the viper genus Echis [62] and, given the propensity for 3FTxs to be extremely selective $[23,25,26,44]$, it is possible that some of these aquatic elapids could contain invertebrate-specific toxins. Future work should test marine invertebrate prey $\mathrm{nAChR}$ orthosteric mimotopes against these aquatic elapid venoms.

In the present study, Aipysurus laevis venom had a very high binding affinity in comparison to all other venoms tested and is one of the highest binding of all elapid venoms tested on this BLI assay to date $[54,55]$. This species is a generalist feeder, predating on a large diversity of fish $(>17$ different families), fish eggs and marine invertebrates (e.g., cephalopods, crustaceans) $[6,7,63]$. This type of diet may be a factor explaining why $A$. laevis venom would seem more broadly potent across the different taxa types, since needing to immobilise a broader taxonomical variety of prey types appears to require 
less specific and more general acting 3FTxs [64]. These data may further support the idea that diet breadth can mediate venom potency in relation to prey-specificity [64].

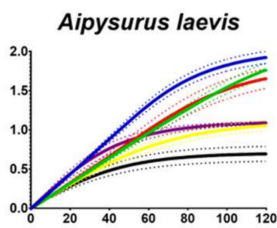

Hydrophis major
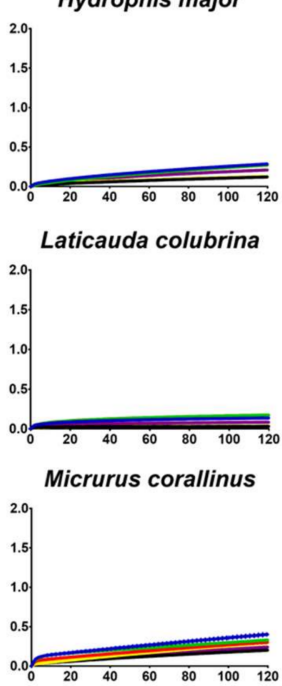
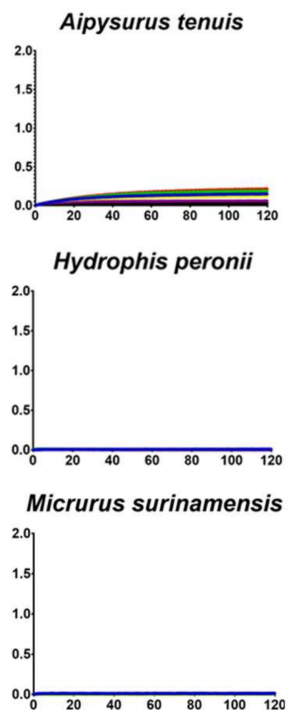

Naja melanoleuca

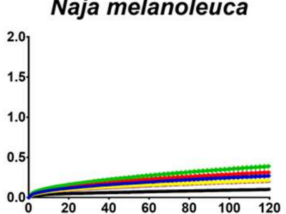

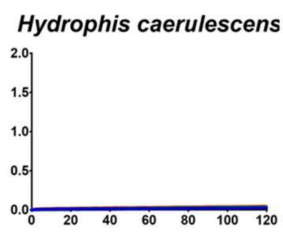

Hydrophis schistosus

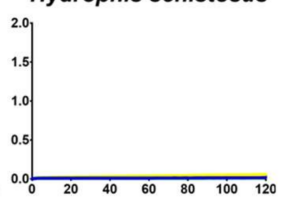

Naja annulata

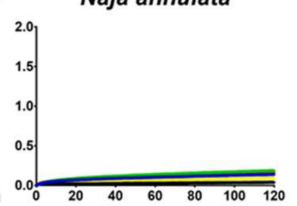

Crotalus horridus (-ve)

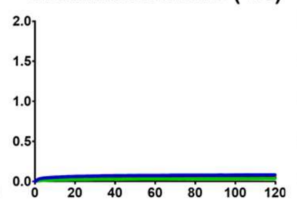

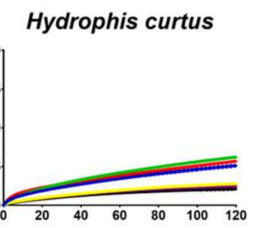

Hydrophis stokesii
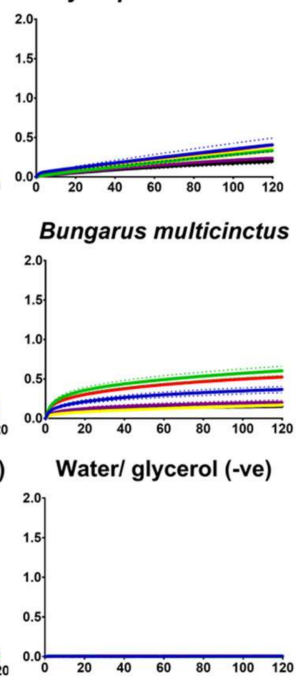

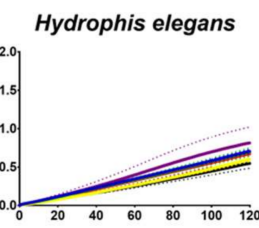

Hydrophis zweifeli
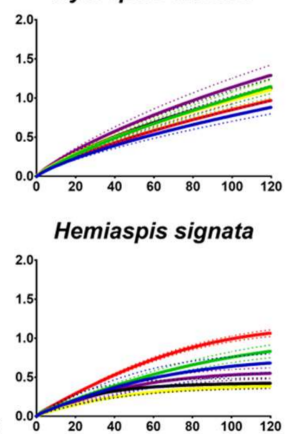

- Fish

- Amphibian

Lizard

- Bird/ Eel

- Rodent

- Human

Figure 1. A binding comparison of crude venom from 17 species of aquatic elapids across $\alpha-1 \mathrm{nAChR}$ mimotopes (fish, amphibian, lizard, bird/eel (both share the same sequence), rodent and human representatives). The two negative (-ve) controls are Crotalus horridus and 1:1 water/glycerol. Crotalus horridus was chosen as there is no evidence that this species utilises nAChR targeting neurotoxins, but will give a comparison of a venom that is rich in large non-binding toxin types (e.g., $\mathrm{PLA}_{2} \mathrm{~s}$, SVSPs and SVMPs $[65,66]$ ) which may cause a greater light shift than the water/glycerol -ve control. The Y-axis shows wavelength shift ( $\mathrm{nm}$ ) of the association (Ka binding step); the $\mathrm{X}$-axis displays seconds (for the 120 -s association period). All venoms were tested in triplicate. The dots surrounding the curve lines are error bars based on SEM values with $n=3$. All raw data can be found in Supplementary File S1.

Some species, such as A. tenuis, H. stokesii, H. major, L. colubrina and N. annulata, although having toxins that bound to the mimotopes, were relatively low-binding in comparison to other species as A. laevis, H. elegans, $H$. curtus and two of the terrestrial comparison species; B. multicinctus and Hemiaspis signata. This low binding has been previously suggested to potentially be due to the proportions of 3FTxs within the venom [55], i.e., a low concentration of 3FTx might give a weaker binding detection than a venom with high concentrations of 3FTxs. However, this does not seem likely in the case of many of these aquatic elapids, as their venoms have been shown to be dominated by 3FTxs in high proportions [47-51]. Furthermore, the venoms of Hydrophis caerulescens, H. peronii, H. schistosus and M. surinamensis did not bind to any mimotope (Figure 1). This is despite previous studies on some of these same species showing postsynaptic neurotoxicity [9] and with clinical reports showing predominantly neurotoxic symptoms $[67,68]$. Thus, the low/lack of binding may be that the predominant neurotoxic targeting of these venoms is either at the presynaptic junction or that the toxins are targeting allosterically (binding to the $\mathrm{nAChR}$ at a site other than the orthosteric). Consequently, while some venoms did not bind to the orthosteric site, this does not preclude other mechanisms of neurotoxicity being present. 
Thus, to determine if the venoms were neurotoxic in a presynaptic or allosteric manner, an in vitro neurotoxicity chick-biventer cervicis nerve muscle preparation (CBCNM) assay was used to assess the venoms that lacked orthosteric binding (Figure 1). The results from the CBCNM assay indicate that the venoms of $H$. caerulescens, $H$. peronii and $M$. surinamensis rapidly abolished twitch response (Figure 2A), by acting upon nAChRs at the postsynaptic junction, as indicated by the lack of response to exogenous ACh and CCh (Figure 2B). Although H. schistosus did not bind to the postsynaptic orthosteric site (Figure 1), there was not enough crude venom to test on CBCNM. However, H. schistosus has been previously shown to exhibit potent postsynaptic nAChR activity [9].
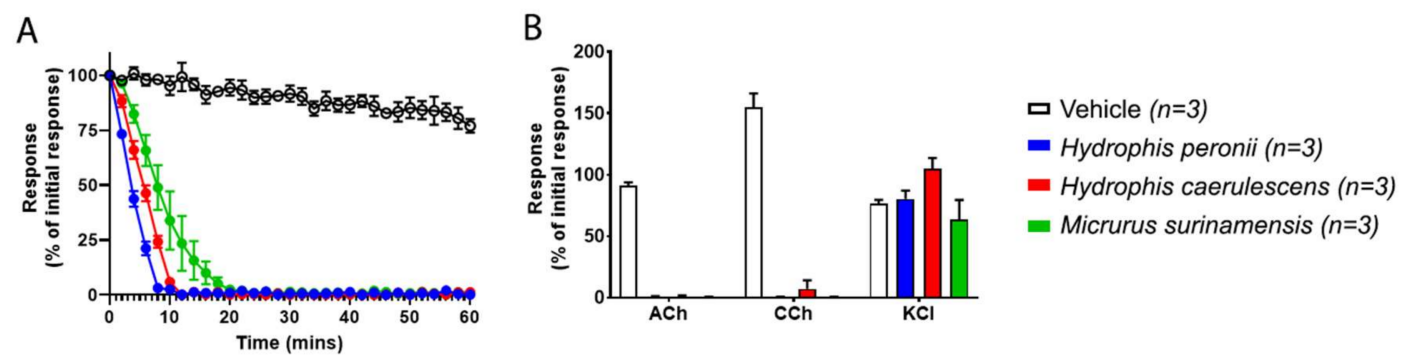

Figure 2. In vitro neurotoxicity using the chick-biventer cervicis nerve muscle preparation (CBCNM); (A) Inhibition of indirect twitches in the CBCNM by Hydrophis peronii (blue), H. caerulescens (red) and Micrurus surinamensis (green). Vehicle (white) is the control. (B) The effect of venoms on the contractile response to exogenous agonists acetylcholine (ACh), carbachol (CCh), and potassium chloride (KCI). All venoms were tested in triplicate $(n=3)$.

Since the BLI assay to test orthosteric postsynaptic activity did not detect any binding for $H$. caerulascens, $H$. peronii and M. surinamensis (Figure 1), and the CBCNM assay, which can detect differential targeting of the post- and presynaptic nerve terminal, revealed potent postsynaptic nAChR action (Figure 2), the most parsimonious explanation for these results is that the venoms are indeed acting allosterically. To date, only one allosterically targeting 3FTx has been identified, however, this only seems to be allosteric toward muscarinic receptors (mAChRs) [35]. Given this, and the notion that there is a wide diversity of 3FTx functional activities, it is no surprise that allosteric nAChR inhibition might have also evolved. Furthermore, it might be that low binding venoms (Figure 1) may indeed also contain these allosteric targeting toxins in combination with orthosteric. For example, N. annulata, which bound only weakly to the orthosteric site (Figure 1) has been shown previously to be potently neurotoxic at the postsynaptic junction when tested on the CBCNM [69]. Therefore, while this species does not bind strongly to the orthosteric site, it may be likely that other toxins are present in the venom that bind to the allosteric site of the postsynaptic nAChR, causing an overall greater potency.

Future research should assess if these venoms are indeed allosteric by utilising a two-electrode voltage-clamp assay. Further, a similar method, as previously mentioned [70], in combination with the BLI assay used here to test a series of overlapping mimotopes which correspond to the whole length of the $\alpha-1 \mathrm{nAChR}$, could also test for allosteric binding.

Venom compositions were determined using LC-MS/MS to observe any differences or similarities between the venoms of the species that bound allosterically and the venoms that bound to the orthosteric site. The only commonality between the LC-MS/MS results from the species that show possible allosteric targeting is that they all contain Type I 3Ftxs (Figure 3). Comparisons between Type I and Type II 3Ftxs highlight that they display differential targeting toward nAChRs [13]. For example, Type I 3FTxs are much faster acting than Type II, associating 6-7 fold faster and dissociating 5-9 fold faster, indicating a faster but weaker binding of Type I [13]. Type I 3FTxs are also more reversible than Type II [13]. It might be that these differences in binding between Type I and Type II 3FTxs are suggestive of allosteric targeting by Type I 3FTxs. It is possible that there is a biochemical trade-off with binding allosterically, with it being a quicker acting toxin but weaker in binding strength. The evolution 
of these faster acting allosteric toxins is likely to occur given a strong selection pressure to immobilise prey with either a high escape potential or a greater risk of prey handling.

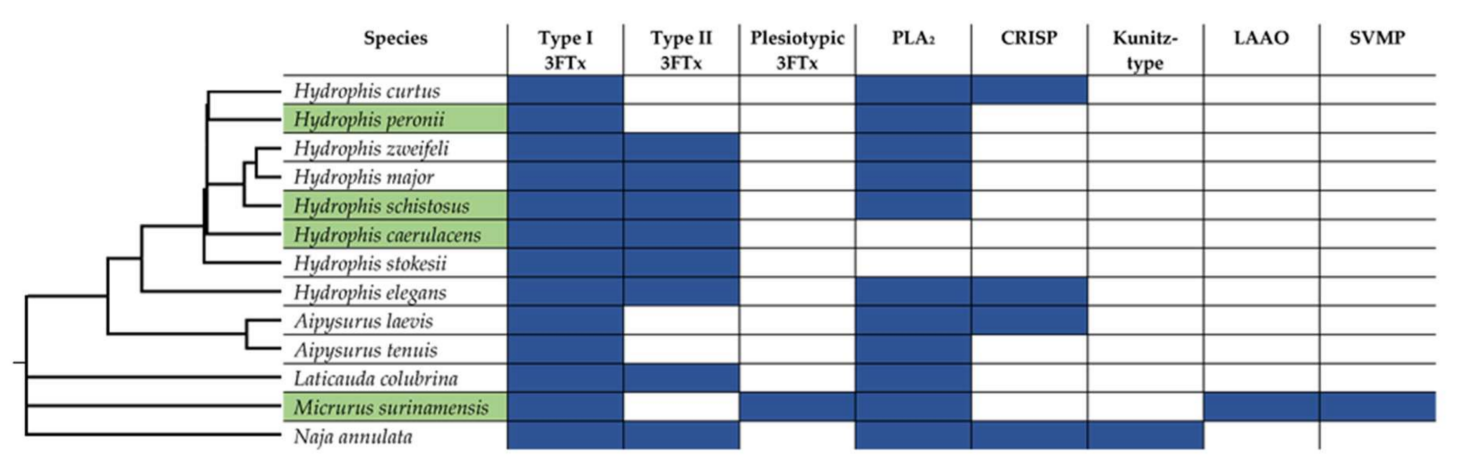

Figure 3. LC-MS/MS results highlighted by their toxin class representative matches from ProteinPilot ${ }^{\mathrm{TM}}$ v. 5.0. Toxin family abbreviations are as follows: Type I3FTx, short-chain three-finger toxin; Type II 3FTx, long-chain three finger toxin; Plesiotypic 3FTx, plesiotypic three-finger toxin; PLA2, phospholipase $\mathrm{A}_{2}$; CRISP, cysteine-rich secretory peptide; Kunitz-type; kunitz-type protease inhibitor; LAAO, L-amino acid oxidase; SVMP, snake venom metalloprotease. Blue rectangles indicate the toxin type was matched from the LC-MS/MS results. Species names highlighted in green were species that did not bind orthosterically to postsynaptic nAChR mimotopes (Figure 1). Phylogeny was taken from Timetree.org and adjusted using recent phylogenetic data [4]. All LC-MS/MS raw data output from ProteinPilot ${ }^{\mathrm{TM}} \mathrm{v}$. 5.0 can be found in Supplementary File S2.

A comprehensive study on the diets of marine snakes [6] revealed that $H$. caerulescens and H. peronii feed predominantly on Trypauchenidae species, which are burrowing gobies. This predominant diet of burrowing fish might be enough of a selective pressure to push the neurotoxic venom of these sea snakes to allosteric binding, compared to that of more generalist feeders. Burrowing fish would certainly have a higher escape potential than other prey. Similarly, H. schistosus is thought to feed predominantly on ariid and plotosid catfish [6,7], which are known for their defensive spines associated with venom [71,72]. Again, it might be that faster acting (possibly allosteric) neurotoxins are more beneficial for use against these prey types, since there is a greater risk of injury due to defensive envenomation. Therefore prey retaliation is another potential shaping pressure for aquatic venoms, as has been suggested for terrestrial lineages such as Calliophis bivirgatus feeding upon other venomous snakes [36].

In light of this, it is likely that many of the species with low orthosteric binding might also contain allosteric toxins, some having previously been shown to potently target the postsynaptic junction on CBCNM (e.g., N. annulata [69] and L. colubrina [9]).

Clearly, there is a vast gap in the literature regarding the questions posed here, particularly the presence of potential allosteric nAChR toxins and how, if at all, these differ functionally to the orthosteric nAChR toxins in their binding efficiency and immobilisation speed.

In summary, this research set out to assess the potential for prey-specific targeting of aquatic elapid venoms to that of the nAChR orthosteric site of a plethora of taxa types. During the investigation, many unexpected results posed further research questions concerning the functional targeting of the neurotoxic components of some aquatic elapid venoms. No true prey-specificity was observed, but some species, such as Aipysurus laevis, showed marginal prey-selectivity with fish, amphibian and bird/eel targets as its highest binding targets. However, due to the use of broad taxonomic representative mimotopes (which for some are fairly conserved across taxa groups), there is still the possibility that prey-specificity may occur. Some aquatic elapids were either low-binding or did not bind to the nAChR orthosteric mimotopes, which led the authors to hypothesise the presence of either presynaptic or allosteric targeting toxins. The venoms of species that did not bind to the BLI assay were 
thus further tested utilising the CBCNM assay to assess if they target presynaptically or are allosteric binders. The results indicated that their venoms blocked postsynaptic nAChRs and thus target these receptors allosterically. This further suggests that allosteric binding toxins may play a more prominent role in aquatic elapid neurotoxicity than previously realised.

Future research should endeavour to assess the venom binding of aquatic elapids to that of mimotope sequences that are species-specific to the diet of these snakes. Further work also is needed to assess if the venoms of some species do indeed contain allosteric nAChR targeting toxins and to further attempt to isolate and characterise them. This would potentially shed light on a new functional class of snake venom toxins with exciting new avenues for both evolutionary and pharmacological fields.

\section{Materials and Methods}

\subsection{Venom Collection and Preparation}

Pooled venoms were obtained from the pre-existing, long-term cryogenic research sample collection of the Toxin Evolution Lab, with no animal use specifically for this project except for the Micrurus species which were wild-collected under the conditions of ICMBio permits 57585 and 66597 linked to animal ethics approval from the Instituto Butantan Ethics Committee CEUA n 4479020217 (issued on 22 March 2017) and CEUA no 3159250919 (issued 23 October 2019), respectively. All venom samples were lyophilised and reconstituted in double deionised water $\left(\mathrm{ddH}_{2} \mathrm{O}\right)$, and then centrifuged $\left(4{ }^{\circ} \mathrm{C}, 10 \mathrm{~min}\right.$ at 14,000 relative centrifugal force $\left.(\mathrm{RCF})\right)$. The supernatant was then made into a working stock $(1 \mathrm{mg} / \mathrm{mL})$ in $50 \%$ glycerol to prevent freezing at $-20^{\circ} \mathrm{C}$. The concentrations of working stocks were determined in triplicate using a NanoDrop 2000 UV-Vis Spectrophotometer (Thermo Fisher, Sydney, Australia) at an absorbance wavelength of $280 \mathrm{~nm}$.

\subsection{Mimotope Production and Preparation}

Following methods from a previously developed assay [55,56], a 13-14 amino acid mimotope of the vertebrate $\alpha-1 \mathrm{nAChR}$ orthosteric site was synthesised by GenicBio Ltd. (Shanghai, China), designed upon specification obtained from chrna1 sequences from UniProt and GenBank databases.

Accession codes for the amino acid sequences of the $\alpha-1 \mathrm{nAChR}$ orthosteric site for each taxa were as follows: fish $\alpha-1$ (uniprot P02710), amphibian $\alpha-1$ (uniprot F6RLA9), lizard $\alpha-1$ (genbank XM_015426640), bird/eel $\alpha$-1 (uniprot E1BT92 and uniprot P09688), rodent $\alpha-1$ (uniprot P25108), human $\alpha-1$ (uniprot P02708).

The Cys-Cys of the native mimotope was replaced during peptide synthesis with Ser-Ser to avoid uncontrolled postsynthetic thiol oxidation. The Cys-Cys bond in the nAChR binding region does not participate directly in analyte-ligand binding $[20,73,74]$, thus, replacement to Ser-Ser is not expected to have any effect on the analyte-ligand complex formation. However, the presence of the Cys-Cys bridge is key in the conformation of the interaction site of whole receptors [75]. As such, we suggest that direct comparisons of kinetics data, such as Ka or KD, between $\mathrm{nAChR}$ mimotopes and whole receptor testing should be avoided, or at least approached with caution. Mimotopes were further synthesised to a biotin linker bound to two aminohexanoic acid (Ahx) spacers, forming a $30 \AA$ Ainker.

Mimotope dried stocks were solubilised in 100\% dimethyl sulfoxide (DMSO) and diluted in $\mathrm{ddH}_{2} \mathrm{O}$ at 1:10 dilution to obtain a stock concentration of $50 \mu \mathrm{g} / \mathrm{mL}$ in $10 \%$ DMSO. Stocks were stored at $-80^{\circ} \mathrm{C}$ until required.

\subsection{Biolayer Interferometry (BLI)}

Full details of the developed assay, including a full methodology and data analysis, can be found in the validated protocol [56] and further data using this protocol [54,55]. In summary, the BLI assay was performed on the Octet Red 96 system (ForteBio, Fremont, CA, USA). Venom (analyte) samples were diluted at 1:20 (a final experimental concentration of $50 \mu \mathrm{g} / \mathrm{mL}$ per well). Mimotope aliquots were diluted at 1:50 (a final concentration of $1 \mu \mathrm{g} / \mathrm{mL}$ per well). The assay running buffer was 1X DPBS with 
$0.1 \%$ BSA and $0.05 \%$ Tween-20. Prior to experimentation, Streptavidin biosensors were hydrated in the running buffer for 30-60 min, whilst on a shaker at 2.0 revolutions per minute (RPM). The dissociation of analytes occurred using a standard acidic solution glycine buffer $(10 \mathrm{mM}$ glycine $(\mathrm{pH} 1.5-1.7)$ in $\mathrm{ddH}_{2} \mathrm{O}$ ). Raw data are provided in Supplementary File S1. All data obtained from BLI on Octet Red 96 system (ForteBio) were processed in accordance with the validation of this assay [56]. The association step data (in triplicate) were obtained in an Excel.csv file extracted from raw outputs of the Octet Red 96 system and then imported into Prism8.0 software (GraphPad Software Inc., La Jolla, CA, USA) and graphs were produced.

\subsection{Sample Preparation for Mass Spectrometry (LC-MS/MS)}

Powdered venom samples were reduced and alkylated. The protocol was as follows: $20 \mu \mathrm{L}$ of $8 \mathrm{M}$ urea was added to $5 \mu \mathrm{g}$ of powdered venom and vortexed. A total of $10 \mu \mathrm{L}$ of $15 \mathrm{mM}$ dithiothreitol (DTT) was further added, vortexed and then the sample incubated at $56{ }^{\circ} \mathrm{C}$ for $30 \mathrm{~min}$. The sample was then cooled to room temperature (RT) and $10 \mu \mathrm{L}$ of $100 \mathrm{mM}$ iodoacetamide (IAA) added and then further incubated at RT for 30 min with reduced light. A further $10 \mu \mathrm{L}$ of $15 \mathrm{mM}$ DTT was added and incubated for $30 \mathrm{~min}$ at RT. $50 \mu \mathrm{L}$ of $40 \mathrm{mM}$ ammonium bicarbonate (ABC) was added, followed by $10 \mu \mathrm{L}$ of trypsin solution (trypsin w/ 5\% 1mM hydrochloric acid (HCL) and 95\% ABC) on ice. The samples were then incubated at $37^{\circ} \mathrm{C}$ for $24 \mathrm{~h}$ and then further lyophilised.

The lyophilised reduced and alkylated venom samples were brought up in $0.1 \%$ triflouric acid (TFA). The samples were filtered via Millipore ZipTips ${ }^{\circledR}$ using the following protocol: tips were wetted with $100 \%$ acetonitrile $(\mathrm{ACN})(3 \times 10 \mu \mathrm{L})$ then equilibrated with $10 \mu \mathrm{L} 5 \% \mathrm{ACN} / 0.1 \%$ TFA $(3 \times 10 \mu \mathrm{L})$. Samples were then loaded and pipetted up and down twice the volume of sample. Tips were then washed with $5 \%$ ACN/0.1\% TFA $(3 \times 10 \mu \mathrm{L})$. Samples were eluted with 80\% ACN/0.1\% TFA $(10 \mu \mathrm{L})$ in a new tube. Samples were then lyophilised and later resuspended in $20 \mu \mathrm{L}$ of $5 \%$ ACN/0.1\% TFA for LC-MS/MS.

\subsection{Mass Spectrometry (LC-MS/MS)}

Samples had an injection volume of $6 \mu \mathrm{L}$ and were separated using reversed-phase chromatography on a Dionex Ultimate 3000 RSLC nano-system. Using a flow rate of $30 \mu \mathrm{L} / \mathrm{min}$, samples were desalted on a Thermo PepMap 100 C18 trap $(0.3 \times 5 \mathrm{~mm}, 5 \mu \mathrm{m})$ for $5 \mathrm{~min}$, followed by separation on an Acclaim PepMap RSLC C18 $(150 \mathrm{~mm} \times 75 \mu \mathrm{m})$ column at a flow rate of $300 \mathrm{~nL} / \mathrm{min}$. A gradient of $5-50 \%$ buffer B over $40 \mathrm{~min}, 50-98 \%$ B over $3 \mathrm{~min}$, and held at $98 \%$ B for 6 min was used, where buffer $A=1 \%$ $\mathrm{ACN} / 0.1 \% \mathrm{FA}$ and buffer $\mathrm{B}=80 \% \mathrm{ACN} / 0.1 \% \mathrm{FA}$ was used to separate peptides. Eluted peptides were directly analysed on an Orbitrap Elite mass spectrometer (Thermo) using an NSI electrospray interface. Source parameters included a capillary temperature of $275^{\circ} \mathrm{C}$; S-Lens RF level at $63 \%$; source voltage of $2.1 \mathrm{kV}$ and maximum injection times of $200 \mathrm{~ms}$ for MS and $150 \mathrm{~ms}$ for MS2. Instrument parameters included an FTMS scan across m/z range 350-1800 at 60,000 resolution followed by CID fragmentation of the top 10 peptides in the ion trap. Dynamic ion exclusion was employed using a $15 \mathrm{~s}$ interval. Charge state screening was enabled with rejection of +1 charged ions and monoisotopic precursor selection enabled.

Data were converted to mascot generic format (mgf) using the msConvert software (ProteoWizard, v3.0) and searched using Protein Pilot ${ }^{\mathrm{TM}}$ v. 5.0 (Sciex). An Elapidae and Hydrophiidae protein database was downloaded from UniProt and the data were matched against toxin from these databases in ProteinPilot ${ }^{\mathrm{TM}}$ v5.0. Raw data output from ProteinPilot ${ }^{\mathrm{TM}}$ v. 5.0 is accessible in Supplementary File S2.

\subsection{Isolated Chick-Biventer Cervicis Nerve-Muscle Preparation}

Chicks aged 4 to 10 days were euthanized with $\mathrm{CO}_{2}$ (animal ethics MARP/2017/147 was approved by Monash University Ethics Committee on 12 May 2017). After dissection, the biventer cervicis nerve muscle (CBCNM) preparations were mounted under $1 \mathrm{~g}$ tension in $5 \mathrm{~mL}$ organ baths containing physiological salt solution $\left(\mathrm{NaCl}, 118.4 \mathrm{mM} ; \mathrm{KCl}, 4.5 \mathrm{mM} ; \mathrm{MgSO} 4,1.2 \mathrm{mM} ; \mathrm{KH} 2 \mathrm{PO} 4,1.2 \mathrm{mM} ; \mathrm{CaCl}_{2}\right.$, 
$2.5 \mathrm{mM} ; \mathrm{NaHCO}_{3}, 25 \mathrm{mM}$; and glucose, $\left.11.1 \mathrm{mM}\right)$. Organ baths were maintained at $34{ }^{\circ} \mathrm{C}$ and bubbled with carbogen $\left(95 \% \mathrm{O}_{2} ; 5 \% \mathrm{CO}_{2}\right)$. Electrodes were placed around the tendon of the biventer muscle and electrical stimulation at the motor nerve $(0.2 \mathrm{~ms}$ duration, $0.1 \mathrm{~Hz}$, supramaximal $\mathrm{V})$ using a Grass S88 stimulator (Grass Instruments, Quincy, MA, USA) evoked indirect twitches. Selective stimulation of the nerve was confirmed by the abolition of twitches with d-tubocurarine $(10 \mu \mathrm{M})$, a nAChR competitive antagonist. Tissues were then washed repeatedly with physiological salt solution to restore twitch responses to nerve stimulation. The stimulation was ceased, and the contractile responses to acetylcholine (ACh, $1 \mathrm{mM}$ for $30 \mathrm{~s}$ ), carbochol (CCh, $20 \mu \mathrm{M}$ for $60 \mathrm{~s}$ ), and potassium chloride $(\mathrm{KCl}, 40 \mathrm{mM}$ for $30 \mathrm{~s})$ were obtained and recorded. The organ bath was then washed, and electrical stimulation was resumed and maintained for $30 \mathrm{~min}$ to allow the preparation to equilibrate. Venom $(10 \mu \mathrm{g} / \mathrm{mL})$ was added to the organ bath and the twitch height was recorded until the abolition of twitch response or was stopped after a $1 \mathrm{~h}$ period. The stimulator was turned off again and the bath was washed. Contractile responses to $\mathrm{ACh}, \mathrm{CCh}$ and $\mathrm{KCl}$ were obtained again to compare with responses prior to venom addition. The twitch responses to electrical stimulations and contractile responses to agonists (ACh, CCh, and $\mathrm{KCI}$ ) were measured using a Grass FT03 force displacement transducer (Grass Instruments, Quincy, MA, USA) and recorded on a PowerLab system (ADInstruments Pty Ltd., Bella Vista, NSW, Australia). The data were then converted into figures using Prism8.0 software (GraphPad Software Inc., La Jolla, CA, USA).

Supplementary Materials: Supplementary materials can be found at http://www.mdpi.com/1422-0067/21/19/ 7377/s1.

Author Contributions: Conceptualisation, R.J.H. and B.G.F.; data acquisition, R.J.H., T.M.H., A.N.; funding acquisition, B.G.F.; investigation, R.J.H., T.M.H., A.N.; methodology, R.J.H., C.N.Z., T.M.H., A.N., W.C.H., B.G.F.; resources, R.J.H., N.J.Y., A.N., W.C.H., D.H., N.D., J.A.P.J., B.G.F.; writing—original manuscript, R.J.H.; writing - review and editing, R.J.H., N.J.Y., C.N.Z., B.G.F.; supervision, B.G.F. All authors have read and agreed to the published version of the manuscript.

Funding: R.J.H.: N.J.Y. and C.N.Z. was supported by the University of Queensland international and domestic PhD scholarship fund. T.M.H. was supported by a PhD scholarship funded from an Australian National Health and Medical Research Council (NHMRC) Centres for Research Excellence Grant (ID:1110343). B.G.F was funded by Australian Research Council Discovery Project DP190100304, JP was funded by Fundação de Amparo à Pesquisa do Estado de São Paulo (2018/25749-8).

Conflicts of Interest: The authors declare no conflict of interest.

\section{Abbreviations}

$\begin{array}{ll}\text { nAChR } & \text { Nicotinic acetylcholine receptor } \\ \text { mAChR } & \text { Muscarinic acetylcholine receptor } \\ \text { 3FTx } & \text { Three-finger toxin } \\ \text { PLA }_{2} & \text { Phospholipase } \mathrm{A}_{2} \\ \text { CRISP } & \text { Cystine -rich secretory protein } \\ \text { Kunitz-type } & \text { Kunitz-type protease inhibitor } \\ \text { LAAO } & \text { L-Amino acid oxidase } \\ \text { SVMP } & \text { Snake venom metalloprotease } \\ \text { SVSP } & \text { Snake venom serine protease } \\ \text { BLI } & \text { Biolayer interferometry } \\ \text { CBCNM } & \text { Chick-biventer cervicis nerve muscle } \\ \text { ACh } & \text { Acetylcholine } \\ \text { CCh } & \text { Carbochol } \\ \text { KCl } & \text { Potassium chloride }\end{array}$

\section{References}

1. Young, B. The influences of the aquatic medium on the prey capture system of snakes. J. Nat. Hist. 1991, 25, 519-531. [CrossRef] 
2. Shine, R. Constraints on reproductive investment: A comparison between aquatic and terrestrial snakes. Evolution 1988, 42, 17-27. [CrossRef] [PubMed]

3. Gopalakrishnakone, P.; Kochva, E. Venom glands and some associated muscles in sea snakes. J. Morphol. 1990, 205, 85-96. [CrossRef] [PubMed]

4. Lee, M.S.; Sanders, K.L.; King, B.; Palci, A. Diversification rates and phenotypic evolution in venomous snakes (Elapidae). R. Soc. Open Sci. 2016, 3, 150277. [CrossRef] [PubMed]

5. Li, M.; Fry, B.; Kini, R.M. Eggs-only diet: Its implications for the toxin profile changes and ecology of the marbled sea snake (Aipysurus eydouxii). J. Mol. Evol. 2005, 60, 81-89. [CrossRef]

6. Glodek, G.S.; Voris, H.K. Marine snake diets: Prey composition, diversity and overlap. Copeia 1982, 661-666. [CrossRef]

7. Voris, H.K.; Voris, H.H. Feeding strategies in marine snakes: An analysis of evolutionary, morphological, behavioral and ecological relationships. Am. Zool. 1983, 23, 411-425. [CrossRef]

8. Li, M.; Fry, B.G.; Kini, R.M. Putting the brakes on snake venom evolution: The unique molecular evolutionary patterns of Aipysurus eydouxii (Marbled sea snake) phospholipase A2 toxins. Mol. Biol. Evol. 2005, 22, 934-941. [CrossRef]

9. Chetty, N.; Du, A.; Hodgson, W.C.; Winkel, K.; Fry, B.G. The in vitro neuromuscular activity of Indo-Pacific sea-snake venoms: Efficacy of two commercially available antivenoms. Toxicon 2004, 44, 193-200. [CrossRef]

10. Kishida, T.; Hikida, T. Degeneration patterns of the olfactory receptor genes in sea snakes. J. Evol. Biol. 2010, 23, 302-310. [CrossRef]

11. Doolittle, R.F. Step-by-step evolution of vertebrate blood coagulation. Proc. Cold Spring Harb. Symp. Quant. Biol. 2009, 74, 35-40. [CrossRef] [PubMed]

12. Cerenius, L.; Söderhäll, K. Coagulation in invertebrates. J. Innate Immun. 2011, 3, 3-8. [CrossRef] [PubMed]

13. Barber, C.M.; Isbister, G.K.; Hodgson, W.C. Alpha neurotoxins. Toxicon 2013, 66, 47-58. [CrossRef] [PubMed]

14. Nirthanan, S.; Gwee, M.C. Three-finger $\alpha$-neurotoxins and the nicotinic acetylcholine receptor, forty years on. J. Pharmacol. Sci. 2004, 94, 1-17. [CrossRef]

15. Chang, C. The action of snake venoms on nerve and muscle. In Snake Venom; Springer: Berlin/Heidelberg, Germany, 1979; pp. 309-376.

16. Servent, D.; Ménez, A. Snake neurotoxins that interact with nicotinic acetylcholine receptors. In Handbook of Neurotoxicology; Springer: Berlin/Heidelberg, Germany, 2002; pp. 38-425.

17. Dellisanti, C.; Yao, Y.; Stroud, J.C.; Wang, Z.-Z.; Chen, L. Structural determinants for $\alpha$-neurotoxin sensitivity in muscle $\mathrm{nAChR}$ and their implications for the gating mechanism. Channels 2007, 1, 234-237. [CrossRef]

18. Dellisanti, C.D.; Yao, Y.; Stroud, J.C.; Wang, Z.-Z.; Chen, L. Crystal structure of the extracellular domain of nAChR $\alpha 1$ bound to $\alpha$-bungarotoxin at $1.94 \AA$ resolution. Nat. Neurosci. 2007, 10, 953-962. [CrossRef]

19. Kachalsky, S.G.; Jensen, B.S.; Barchan, D.; Fuchs, S. Two subsites in the binding domain of the acetylcholine receptor: An aromatic subsite and a proline subsite. Proc. Natl. Acad. Sci. USA 1995, 92, 10801-10805. [CrossRef]

20. Tzartos, S.; Remoundos, M.S. Fine localization of the major alpha-bungarotoxin binding site to residues alpha 189-195 of the Torpedo acetylcholine receptor. Residues 189, 190, and 195 are indispensable for binding. J. Biol. Chem. 1990, 265, 21462-21467.

21. Bracci, L.; Lozzi, L.; Lelli, B.; Pini, A.; Neri, P. Mimotopes of the nicotinic receptor binding site selected by a combinatorial peptide library. Biochemistry 2001, 40, 6611-6619. [CrossRef]

22. Gotti, C.; Clementi, F. Neuronal nicotinic receptors: From structure to pathology. Prog. Neurobiol. 2004, 74, 363-396. [CrossRef]

23. Fry, B.G.; Lumsden, N.G.; Wüster, W.; Wickramaratna, J.C.; Hodgson, W.C.; Kini, R.M. Isolation of a neurotoxin ( $\alpha$-colubritoxin) from a nonvenomous colubrid: Evidence for early origin of venom in snakes. J. Mol. Evol. 2003, 57, 446-452. [CrossRef] [PubMed]

24. Heyborne, W.H.; Mackessy, S.P. Identification and characterization of a taxon-specific three-finger toxin from the venom of the Green Vinesnake (Oxybelis fulgidus; family Colubridae). Biochimie 2013, 95, 1923-1932. [CrossRef] [PubMed]

25. Pawlak, J.; Mackessy, S.P.; Fry, B.G.; Bhatia, M.; Mourier, G.; Fruchart-Gaillard, C.; Servent, D.; Ménez, R.; Stura, E.; Ménez, A. Denmotoxin, a three-finger toxin from the colubrid snake Boiga dendrophila (Mangrove Catsnake) with bird-specific activity. J. Biol. Chem. 2006, 281, 29030-29041. [CrossRef] [PubMed] 
26. Pawlak, J.; Mackessy, S.P.; Sixberry, N.M.; Stura, E.A.; Le Du, M.H.; Ménez, R.; Foo, C.S.; Ménez, A.; Nirthanan, S.; Kini, R.M. Irditoxin, a novel covalently linked heterodimeric three-finger toxin with high taxon-specific neurotoxicity. FASEB J. 2009, 23, 534-545. [CrossRef] [PubMed]

27. Fry, B.G.; Scheib, H.; van der Weerd, L.; Young, B.; McNaughtan, J.; Ramjan, S.R.; Vidal, N.; Poelmann, R.E.; Norman, J.A. Evolution of an arsenal: Structural and functional diversification of the venom system in the advanced snakes (Caenophidia). Mol. Cell. Proteom. 2008, 7, 215-246. [CrossRef] [PubMed]

28. Dashevsky, D.; Fry, B.G. Ancient diversification of three-finger toxins in Micrurus coral snakes. J. Mol. Evol. 2018, 86, 58-67. [CrossRef] [PubMed]

29. Quinton, L.; Girard, E.; Maiga, A.; Rekik, M.; Lluel, P.; Masuyer, G.; Larregola, M.; Marquer, C.; Ciolek, J.; Magnin, T. Isolation and pharmacological characterization of AdTx1, a natural peptide displaying specific insurmountable antagonism of the $\alpha 1 \mathrm{~A}$-adrenoceptor. Br. J. Pharmacol. 2010, 159, 316-325. [CrossRef]

30. Rouget, C.; Quinton, L.; Maïga, A.; Gales, C.; Masuyer, G.; Malosse, C.; Chamot-Rooke, J.; Thai, R.; Mourier, G.; De Pauw, E. Identification of a novel snake peptide toxin displaying high affinity and antagonist behaviour for the $\alpha 2$-adrenoceptors. Br. J. Pharmacol. 2010, 161, 1361-1374. [CrossRef]

31. Diochot, S.; Baron, A.; Salinas, M.; Douguet, D.; Scarzello, S.; Dabert-Gay, A.-S.; Debayle, D.; Friend, V.; Alloui, A.; Lazdunski, M. Black mamba venom peptides target acid-sensing ion channels to abolish pain. Nature 2012, 490, 552-555. [CrossRef]

32. De Weille, J.R.; Schweitz, H.; Maes, P.; Tartar, A.; Lazdunski, M. Calciseptine, a peptide isolated from black mamba venom, is a specific blocker of the L-type calcium channel. Proc. Natl. Acad. Sci. USA 1991, 88, 2437-2440. [CrossRef]

33. Harvey, A.L.; Kornisiuk, E.; Bradley, K.N.; Cerveñansky, C.; Durán, R.; Adrover, M.; Sánchez, G.; Jerusalinsky, D. Effects of muscarinic toxins MT1 and MT2 from green mamba on different muscarinic cholinoceptors. Neurochem. Res. 2002, 27, 1543-1554. [CrossRef] [PubMed]

34. Kornisiuk, E.; Jerusalinsky, D.; Cerveñansky, C.; Harvey, A.L. Binding of muscarinic toxins MT $\times 1$ and MT×2 from the venom of the green mamba Dendroaspis angusticeps to cloned human muscarinic cholinoceptors. Toxicon 1995, 33, 11-18. [CrossRef]

35. Mordvintsev, D.Y.; Polyak, Y.L.; Rodionov, D.I.; Jakubik, J.; Dolezal, V.; Karlsson, E.; Tsetlin, V.I.; Utkin, Y.N. Weak toxin WTX from Naja kaouthia cobra venom interacts with both nicotinic and muscarinic acetylcholine receptors. FEBS J. 2009, 276, 5065-5075. [CrossRef] [PubMed]

36. Yang, D.; Deuis, J.; Dashevsky, D.; Dobson, J.; Jackson, T.; Brust, A.; Xie, B.; Koludarov, I.; Debono, J.; Hendrikx, I. The snake with the scorpion's sting: Novel three-finger toxin sodium channel activators from the venom of the long-glanded blue coral snake (Calliophis bivirgatus). Toxins 2016, 8, 303. [CrossRef] [PubMed]

37. Karlsson, E.; Mbugua, P.; Rodriguez-Ithurralde, D. Fasciculins, anticholinesterase toxins from the venom of the green mamba Dendroaspis angusticeps. J. Physiol. 1984, 79, 232-240.

38. Banerjee, Y.; Lakshminarayanan, R.; Vivekanandan, S.; Anand, G.S.; Valiyaveettil, S.; Kini, R.M. Biophysical characterization of anticoagulant hemextin $\mathrm{AB}$ complex from the venom of snake Hemachatus haemachatus. Biophys. J. 2007, 93, 3963-3976. [CrossRef]

39. Banerjee, Y.; Mizuguchi, J.; Iwanaga, S.; Kini, R.M. Hemextin AB complex-a unique anticogulant protein complex from Hemachatus haemachatus (African Ringhals cobra) venom that inhibits clot initiation and factor VIIa activity. J. Biol. Chem. 2005, 280, 42601-42611. [CrossRef]

40. McDowell, R.S.; Dennis, M.S.; Louie, A.; Shuster, M.; Mulkerrin, M.G.; Lazarus, R.A. Mambin, a potent glycoprotein IIb-IIIa antagonist and platelet aggregation inhibitor structurally related to the short neurotoxins. Biochemistry 1992, 31, 4766-4772. [CrossRef]

41. Kini, R.M.; Evans, H.J. A common cytolytic region in myotoxins, hemolysins, cardiotoxins and antibacterial peptides. Int. J. Pept. Protein Res. 1989, 34, 277-286. [CrossRef]

42. Kini, R.M.; Evans, H.J. Role of cationic residues in cytolytic activity: Modification of lysine residues in the cardiotoxin from Naja nigricollis venom and correlation between cytolytic and antiplatelet activity. Biochemistry 1989, 28, 9209-9215. [CrossRef]

43. Da Silva, N.J., Jr.; Aird, S.D. Prey specificity, comparative lethality and compositional differences of coral snake venoms. Comp. Biochem. Physiol. Part C Toxicol. Pharmacol. 2001, 128, 425-456. [CrossRef]

44. Mackessy, S.P.; Sixberry, N.M.; Heyborne, W.H.; Fritts, T. Venom of the Brown Treesnake, Boiga irregularis: Ontogenetic shifts and taxa-specific toxicity. Toxicon 2006, 47, 537-548. [CrossRef] [PubMed] 
45. Hart, A.J.; Isbister, G.K.; O'Donnell, P.; Williamson, N.A.; Hodgson, W.C. Species differences in the neuromuscular activity of post-synaptic neurotoxins from two Australian black snakes (Pseudechis porphyriacus and Pseudechis colletti). Toxicol. Lett. 2013, 219, 262-268. [CrossRef] [PubMed]

46. Hart, A.J.; Isbister, G.K.; Hodgson, W.C. In vitro neurotoxic effects of Pseudechis spp. venoms: A comparison of avian and murine skeletal muscle preparations. Toxicon 2013, 63, 112-115. [CrossRef] [PubMed]

47. Calvete, J.J.; Ghezellou, P.; Paiva, O.; Matainaho, T.; Ghassempour, A.; Goudarzi, H.; Kraus, F.; Sanz, L.; Williams, D.J. Snake venomics of two poorly known Hydrophiinae: Comparative proteomics of the venoms of terrestrial Toxicocalamus longissimus and marine Hydrophis cyanocinctus. J. Proteom. 2012, 75, 4091-4101. [CrossRef]

48. Laustsen, A.H.; Gutiérrez, J.M.; Rasmussen, A.R.; Engmark, M.; Gravlund, P.; Sanders, K.L.; Lohse, B.; Lomonte, B. Danger in the reef: Proteome, toxicity, and neutralization of the venom of the olive sea snake, Aipysurus laevis. Toxicon 2015, 107, 187-196. [CrossRef]

49. Lomonte, B.; Pla, D.; Sasa, M.; Tsai, W.-C.; Solórzano, A.; Ureña-Díaz, J.M.; Fernández-Montes, M.L.; Mora-Obando, D.; Sanz, L.; Gutiérrez, J.M. Two color morphs of the pelagic yellow-bellied sea snake, Pelamis platura, from different locations of Costa Rica: Snake venomics, toxicity, and neutralization by antivenom. J. Proteom. 2014, 103, 137-152. [CrossRef]

50. Pahari, S.; Bickford, D.; Fry, B.G.; Kini, R.M. Expression pattern of three-finger toxin and phospholipase A2 genes in the venom glands of two sea snakes, Lapemis curtus and Acalyptophis peronii: Comparison of evolution of these toxins in land snakes, sea kraits and sea snakes. BMC Evol. Biol. 2007, 7, 175. [CrossRef]

51. Fry, B.G.; Wüster, W.; Ryan Ramjan, S.F.; Jackson, T.; Martelli, P.; Kini, R.M. Analysis of Colubroidea snake venoms by liquid chromatography with mass spectrometry: Evolutionary and toxinological implications. Rapid Commun. Mass Spectrom. 2003, 17, 2047-2062. [CrossRef]

52. Sanz, L.; de Freitas-Lima, L.N.; Quesada-Bernat, S.; Graça-de-Souza, V.K.; Soares, A.M.; Calderón, L.d.A.; Calvete, J.J.; Caldeira, C.A. Comparative venomics of Brazilian coral snakes: Micrurus frontalis, Micrurus spixii spixii, and Micrurus surinamensis. Toxicon 2019, 166, 39-45. [CrossRef]

53. Aird, S.D.; Da Silva, N.J.; Qiu, L.; Villar-Briones, A.; Saddi, V.A.; Pires de Campos Telles, M.; Grau, M.L.; Mikheyev, A.S. Coralsnake venomics: Analyses of venom gland transcriptomes and proteomes of six Brazilian taxa. Toxins 2017, 9, 187. [CrossRef] [PubMed]

54. Harris, R.J.; Zdenek, C.N.; Debono, J.; Harrich, D.; Fry, B.G. Evolutionary Interpretations of Nicotinic Acetylcholine Receptor Targeting Venom Effects by a Clade of Asian Viperidae Snakes. Comp. Biochem. Physiol. Part C Toxicol. Pharmacol. 2020, 236, 108769. [CrossRef] [PubMed]

55. Harris, R.J.; Zdenek, C.N.; Harrich, D.; Frank, N.; Fry, B.G. An appetite for destruction: Detecting prey-selective binding of $\alpha$-neurotoxins in the venom of Afro-Asian elapids. Toxins 2020, 12, 205. [CrossRef]

56. Zdenek, C.N.; Harris, R.J.; Kuruppu, S.; Youngman, N.J.; Dobson, J.S.; Debono, J.; Khan, M.; Smith, I.; Yarski, M.; Harrich, D. A Taxon-Specific and High-Throughput Method for Measuring Ligand Binding to Nicotinic Acetylcholine Receptors. Toxins 2019, 11, 600. [CrossRef] [PubMed]

57. Heatwole, H.; Poran, N.S. Resistances of sympatric and allopatric eels to sea snake venoms. Copeia 1995, 15, 136-147. [CrossRef]

58. Heatwole, H.; Powell, J. Resistance of eels (Gymnothorax) to the venom of sea kraits (Laticauda colubrina): A test of coevolution. Toxicon 1998, 36, 619-625. [CrossRef]

59. Drabeck, D.H.; Dean, A.M.; Jansa, S.A. Why the honey badger don't care: Convergent evolution of venom-targeted nicotinic acetylcholine receptors in mammals that survive venomous snake bites. Toxicon 2015, 99, 68-72. [CrossRef]

60. Takacs, Z.; Wilhelmsen, K.C.; Sorota, S. Cobra (Naja spp.) nicotinic acetylcholine receptor exhibits resistance to erabu sea snake (Laticauda semifasciata) short-chain $\alpha$-neurotoxin. J. Mol. Evol. 2004, 58, 516-526. [CrossRef]

61. Barchan, D.; Kachalsky, S.; Neumann, D.; Vogel, Z.; Ovadia, M.; Kochva, E.; Fuchs, S. How the mongoose can fight the snake: The binding site of the mongoose acetylcholine receptor. Proc. Natl. Acad. Sci. USA 1992, 89, 7717-7721. [CrossRef]

62. Barlow, A.; Pook, C.E.; Harrison, R.A.; Wüster, W. Coevolution of diet and prey-specific venom activity supports the role of selection in snake venom evolution. Proc. R. Soc. Lond. B Biol. Sci. 2009, 276, 2443-2449. [CrossRef]

63. Voris, H. The role of sea snakes (Hydrophiidae) in the trophic structure of coastal ocean communities. J. Mar. Biol. Assoc. India 1972, 14, 429-442. 
64. Lyons, K.; Dugon, M.M.; Healy, K. Diet breadth mediates the prey specificity of venom potency in snakes. Toxins 2020, 12, 74. [CrossRef] [PubMed]

65. Rokyta, D.R.; Wray, K.P.; Margres, M.J. The genesis of an exceptionally lethal venom in the timber rattlesnake (Crotalus horridus) revealed through comparative venom-gland transcriptomics. BMC Genom. 2013, 14, 394. [CrossRef]

66. Rokyta, D.R.; Wray, K.P.; McGivern, J.J.; Margres, M.J. The transcriptomic and proteomic basis for the evolution of a novel venom phenotype within the Timber Rattlesnake (Crotalus horridus). Toxicon 2015, 98, 34-48. [CrossRef]

67. Pardal, P.P.d.O.; Pardal, J.S.d.O.; Gadelha, M.A.d.C.; Rodrigues, L.d.S.; Feitosa, D.T.; Prudente, A.L.d.C.; Fan, H.W. Envenomation by Micrurus coral snakes in the Brazilian Amazon region: Report of two cases. Rev. Inst. Med. Trop. São Paulo 2010, 52, 333-337. [CrossRef] [PubMed]

68. Phillips, C.M. Sea snake envenomation. Dermatol. Ther. 2002, 15, 58-61. [CrossRef]

69. Panagides, N.; Jackson, T.; Ikonomopoulou, M.; Arbuckle, K.; Pretzler, R.; Yang, D.; Ali, S.; Koludarov, I.; Dobson, J.; Sanker, B. How the cobra got its flesh-eating venom: Cytotoxicity as a defensive innovation and its co-evolution with hooding, aposematic marking, and spitting. Toxins 2017, 9, 103. [CrossRef]

70. Chiappinelli, V.A.; Weaver, W.R.; McLane, K.E.; Conti-Fine, B.M.; Fiordalisi, J.J.; Grant, G.A. Binding of native K-neurotoxins and site-directed mutants to nicotinic acetylcholine receptors. Toxicon 1996, 34, 1243-1256. [CrossRef]

71. Harris, R.J.; Jenner, R.A. Evolutionary ecology of fish venom: Adaptations and consequences of evolving a venom system. Toxins 2019, 11, 60. [CrossRef]

72. Wright, J.J. Diversity, phylogenetic distribution, and origins of venomous catfishes. BMC Evol. Biol. 2009, 9, 282. [CrossRef]

73. McLane, K.E.; Wu, X.; Conti-Tronconi, B.M. An $\alpha$-bungarotoxin-binding sequence on the Torpedo nicotinic acetylcholine receptor $\alpha$-subunit: Conservative amino acid substitutions reveal side-chain specific interactions. Biochemistry 1994, 33, 2576-2585. [CrossRef] [PubMed]

74. McLane, K.E.; Wu, X.; Diethelm, B.; Conti-Tronconi, B.M. Structural determinants of $\alpha$-bungarotoxin binding to the sequence segment 181-200 of the muscle nicotinic acetylcholine receptor. $\alpha$-subunit: Effects of cysteine/cystine modification and species-specific amino acid substitutions. Biochemistry 1991, 30, 4925-4934. [CrossRef] [PubMed]

75. Testai, F.D.; Venera, G.D.; Peña, C.; de Jiménez Bonino, M.J.B. Histidine 186 of the nicotinic acetylcholine receptor $\alpha$ subunit requires the presence of the 192-193 disulfide bridge to interact with $\alpha$-bungarotoxin. Neurochem. Int. 2000, 36, 27-33. [CrossRef] 